\title{
SOCIALIZAÇÃO POLITICA DESIGUAL: ELEMENTOS DA “BOA” POLITIZAÇÃO PELA ESCOLA
}

\author{
LORENZO BARRAULT-STELLA ${ }^{1}$
}

\begin{abstract}
RESUMO: Com base em levantamentos etnográficos de pais de diferentes origens sociais na França, este artigo contribui para uma sociologia de socialização política por parte da instituição escolar. Reconhecendo a centralidade da escola no contexto francês, esta pesquisa destaca como a instituição molda os padrões de percepção e as disposições políticas dos pais. Entretanto, esses processos de socialização institucional, baseados nas trajetórias escolares, bem como nas prescrições atuais da escola, são muito desiguais. Enquanto os pais com maiores recursos e mais envolvidos na instituição tendem a se adequar às suas expectativas, os dos meios populares se mostram mais desajustados, o que, por sua vez, alimenta comportamentos políticos que levam ao seu desengajamento.
\end{abstract}

Palavras-chave: Socialização. Politização. Educação. Escola. Pais.

\section{DES SOCIALISATION POLITIQUES INEGALES: ELEMENTS SUR LA «BONNE » POLITISATION PAR L'ECOLE}

RÉSUMÉ: Basé sur des enquêtes ethnographiques auprès de parents de différents milieux sociaux en France, cet article contribue à une sociologie de la socialisation politique par l'institution scolaire. Prenant acte de la centralité de lécole dans le contexte français, cette recherche souligne comment l'institution façonne les schèmes de perception et les dispositions politiques des parents. Mais ces processus de socialisation institutionnelle, reposant sur les trajectoires scolaires comme sur les prescriptions de lécole, se révèlent très inégales. Alors que les parents les mieux dotés et les plus engagés dans l'institution tendent à se conformer à ses attentes, ceux des milieux populaires se révèlent davantage désajustés ce qui, en retour, alimente des comportements politiques de retrait.

Mots clés: Socialisation. Politisation. Education. Ecole. Parents d’élèves.

\section{UNEQUAL POLITICAL SOCIALIZATION: ELEMENTS OF THE 'GOOD’ POLITICIZATION BY THE SCHOOL}

\begin{abstract}
Based on ethnographic surveys of parents from different social backgrounds in France, this article contributes to a sociology of political socialization by the school institution. Acknowledging the centrality of school in the French context,
\end{abstract}

1.French National Center for Scientific Research-Centre de Recherches Politiques et Sociologiques de Paris - Equipe Cultures et Sociétés Urbaines - Paris, France. E-mail : lorenzo.barrault-stella@cnrs.fr

Editora de Seção: Adriana Dragone Silveira 
this research highlights how the institution shapes the perception patterns and political dispositions of parents. However, these processes of institutional socialization, based on school trajectories as well as on the school's present prescriptions, are very unequal. While the parents who are better endowed and more involved in the institution tend to conform to its expectations, those from working class backgrounds are more maladjusted, which in turn feeds political attitudes of withdrawal.

Keywords: Socialisation. Politicisation. Education. School. Parents.

\section{Introdução}

A

s democracias contemporâneas estão sendo atingidas por importantes transformações nos comportamentos políticos dos cidadãos. Desenvolvem-se atitudes de retirada do jogo político, de declínio do interesse e da participação (ROSENSTONE; HANSEN, 1993). A disparada da abstenção, bem como o crescimento do apoio à extrema direita são fenômenos observáveis em diversos países, não só no Ocidente (STEWART; BOBO; HOCHSCHILD, 2017). A França não escapa dessas tendências estruturais (BARRAULT-STELLA; LEHINGUE, 2020): a falta de inscrição nas listas eleitorais e a abstenção crescem regularmente (inclusive nas eleições presidenciais, antes preservadas), os candidatos do Rassemblement National (RN) agregam um apoio cada vez maior, como atesta a ascensão de Marine Le Pen ao segundo turno das eleições presidenciais de 2017. A explicação dessas mudanças nos comportamentos políticos é complexa, mas não pode se limitar a interpretações focadas no presente e apenas na conjuntura política, como fazem certos trabalhos de ciência política (ex.: PERRINEAU, 2017). Isto seria de fato negar as lógicas de formação dos comportamentos políticos e os diversos processos educativos que afetam a (des) politização dos grupos sociais. Este tipo de análise voltaria a ocultar o conjunto dos fenômenos de socialização política, que se apoiam em diversas instâncias (a família, a escola, o trabalho etc.) e garantem a formação e a transmissão de estruturas de percepção e de avaliação do mundo social.

Este artigo pretende contribuir com o estudo desses processos de socialização política no caso da França contemporânea. A análise parte do questionamento do papel, singular na França, da instituição escolar na formação das disposições e dos gostos políticos ${ }^{1}$. Para isso, a pesquisa traz uma abordagem original focada nos comportamentos políticos dos pais de alunos que também são, em grande medida, cidadãos. Trata-se de questionar a socialização política pela instituição, ou seja, de perguntar se a escola contribui para a (des)politização dos pais e, se sim, como e com quais efeitos. Pois embora hoje pareça evidente (de acordo com inúmeros estudos: HYMAN, 1972; DOUNIES, 2019) que a escola molda os posicionamentos políticos dos alunos, seu papel socializador mais amplo sobre as famílias e sobretudo sobre os pais, que também frequentam a instituição, constitui um ponto cego na literatura científica (BARRAULT-STELLA, 2017). A abordagem a partir da instituição também tem a vantagem de permitir uma observação relacional de famílias socialmente muito diversas (BOURDIEU, 1979), já que, ao contrário da maior parte das outras instituições de Estado, a escola na França acolhe todos os grupos sociais devido ao ensino obrigatório. Em comparação com anos 1960-1970, a instituição escolar é hoje frequentada de forma prolongada por crianças das classes populares (o que alguns trabalhos denominaram de "democratização escolar"). Diversas reformas, vinculadas a políticas de ampliação da escolaridade e, de forma mais ampla, a mudanças no Estado de bem-estar social, levaram a transformações significativas na instituição, bem como nas modalidades de formação política de seus "usuários" nas últimas décadas. O olhar voltado aos pais de alunos, sobretudo no nível do ensino 
fundamental, como tratamos neste artigo, autoriza também uma reflexão sobre o peso das etapas de vida na socialização política (PERCHERON, 1989; METTLER; WELSH, 2004): os pais de alunos de 6 a 11 anos estão numa etapa de sua vida familiar que pode ter implicações duradouras em sua relação com a política. Como a socialização, incluindo suas dimensões políticas, é um processo contínuo (DARMON, 2007), que não se limita à primeira infância e ao universo familiar, abre espaço a outras instâncias, como a instituição escolar, quando os indivíduos se tornam pais.

Para estudar esta socialização política pela escola, este artigo se baseia em várias pesquisas etnográficas realizadas na França com pais de alunos desde 2005 (ver BARRAULT-STELLA, 2013). Eu me apoio em uma comparação entre duas investigações realizadas em dois territórios, urbano e rural, feitas a partir de 2013. Essas pesquisas longitudinais aprofundadas analisaram as atitudes políticas dos pais de alunos tanto em períodos rotineiros quanto diante de eventos políticos singulares, como as reformas escolares (a flexibilização dos distritos escolares em 2007, fechamento de salas de aula no meio rural, grande lei para a escola em 2013, mudanças nos ritmos escolares, instauração de 12 alunos por classe em 2017 etc.). O objetivo é compreender e explicar as condições, as modalidades e os efeitos da politização e de diversas formas de engajamento (em associações, pela participação em movimentos de contestação, pelo engajamento em dispositivos participativos etc.) dos pais sob o prisma de sua relação com a instituição escolar e as reformas da educação nacional. Trata-se de contribuir com os debates sobre as desigualdades sociais de politização, voltando o olhar sobre o papel particular da escola francesa como instância de socialização. Isso vem a aprofundar um percurso evocado por Tocqueville (1835), que considerava as associações e participações em atividades como "escolas da democracia". Tais processos já foram identificados por trabalhos que enfatizaram como a participação em organizações coletivas podia conduzir ao desenvolvimento de posicionamentos mais amplos no engajamento cívico e político (por exemplo VERBA; LEHMAN; BRADY, 1995; PUTNAM, 2000; MCADAM; TARROW; TILLY, 2001). No plano empírico, a análise se baseia na pesquisa qualitativa ao longo do tempo junto a famílias de diferentes meios sociais: várias frações da burguesia, grupos profissionais variados das classes médias, camadas desiguais das classes populares. O dispositivo de pesquisa, preocupado em não focar em grupos mobilizados, visava compreender as relações "comuns" com as instituições escolares e estatais: é preciso observar que a grande maioria dos entrevistados não são ativistas políticos regulares ou militantes sindicais, muito embora, como veremos, podem ser politizados e engajados em torno da escola. Essas famílias foram observadas em dois contextos diferentes: um bairro socialmente heterogêneo do norte de Paris, onde diversas minorias étnico-raciais convivem com as classes média e alta; e um vilarejo rural isolado, com uma centena de habitantes, no sudeste da França. No contexto dessas duas pesquisas etnográficas, os pais (mãe e pai quando aplicável) foram entrevistados várias vezes ao longo da vida escolar de seus filhos (sobretudo em momentos de orientação escolar) e observados no espaço local (saída da escola, conselho escolar, reunião de pais de alunos etc.). O desafio desta abordagem processual é variar as situações de observação das famílias em relação com seus posicionamentos: quais são seus comportamentos escolares e políticos quando não está acontecendo nada de especial, no momento das reformas que afetaram as escolas e seus filhos, ou ainda no período eleitoral? Além desses materiais qualitativos, o artigo se baseia secundariamente numa pesquisa quantitativa realizada através de questionário com uma amostra estatisticamente representativa da população francesa ( $\mathrm{N}=2.900)$, em 2016 e 2017 (Panel Elipss - Sciences Po, ANR Profet coordenada por Alexis Spire), que tratava da relação com a escola, a política e os governos na França. Esses materiais permitem apreender a morfologia de certos processos observados de forma intensiva por meio de pesquisas etnográficas.

Este artigo defende a tese de que, na França, onde a escolarização das crianças de 3 a 16 anos se aproxima hoje de $100 \%$ da população, a instituição escolar constitui uma das principais instâncias de (des) politização dos pais de alunos. A escola francesa prevê oficialmente vários canais de "participação" das 
famílias na vida da instituição: a eleição anual de representantes dos pais em cada classe, sua participação nos "conselhos escolares" de cada estabelecimento, o envolvimento dos pais em várias reuniões de consulta sobre a implementação de políticas etc. Mas além desses instrumentos políticos de participação nos debates sobre as reformas escolares, que de fato envolviam uma pequena minoria de pais ${ }^{2}$, é por meio da visão de seus filhos e de suas experiências mais ou menos diretas da escola que os pais são socializados pela instituição escolar e suas políticas reformadoras: de uma forma que varia conforme as classes sociais e suas outras experiências políticas (tanto diacrônicas como sincrônicas), essa socialização modela os padrões de percepção e de avaliação do mundo social e molda as atuações e as práticas políticas das famílias. A exposição adota uma entrada por caso (RAGIN; BECKER, 1992) e está organizada em quatro etapas. 1) A primeira trata da centralidade da instituição escolar para a população francesa, centralidade esta que permite que ela se torne uma instância maior (mas evidentemente não exclusiva) de socialização política para o conjunto dos grupos sociais. 2) A segunda trata do peso do capital escolar e das desigualdades em relação à escola sobre as formas legítimas de politização 3) A terceira aborda as experiências singulares dos pais com maior capital cultural e mais envolvidos com a instituição escolar para enfatizar a socialização política através dos engajamentos políticos em torno da escola. 4) A última etapa reflete a socialização política pela escola de pais oriundos das classes populares, cujos modos de ação parecem desajustados em relação à instituição e às expectativas do campo político. Em suma, o artigo mostra que as socializações políticas pela escola são muito desiguais de acordo com as origens sociais das famílias e suas relações com a instituição, que variam muito também de acordo com as expectativas do Estado: deste ponto de vista, observamos formas mais ou menos "boas" de politização.

\section{Da Influência da Instituição Escolar na França às suas Implicações Sobre os Processos de de Socialização Política}

Numa acepção foucaultiana, “o Estado nada mais é do que o efeito, o perfil, o recorte móvel de uma perpétua estatização, ou de perpétuas estatizações, de transações incessantes que modificam, que deslocam, que subvertem, que fazem deslizar insidiosamente, pouco importa, as fontes de financiamento, as modalidades de investimento, os centros de decisão, as formas e os tipos de controle, as relações entre as autoridades locais, a autoridade central etc." (FOUCAULT, 2004a, p. 79). Além disso, na França, a escola e as políticas escolares fazem parte das instituições de controle da população pelo Estado (FOUCAULT, 2004b). Predominantemente públicas ou controladas pelo Estado (no caso do ensino privado que é "contratado" em mais de 99\%), a instituição escolar francesa afeta fortemente todos os grupos sociais. Se a escola tem essa centralidade, ela está ligada à trajetória histórica do Estado de bem-estar social na França, que integra componentes educativos em virtude das ligações singulares ali estabelecidas entre as famílias, o mercado e os serviços públicos (ESPINGANDERSEN, 1990). Além disso, o ensino é obrigatório na França e garantido pelo Estado. Estimamos que apenas 0,3\% das crianças entre 6 e 16 anos são ensinadas fora da instituição escolar. E mesmo nesses casos residuais, a Educação nacional exerce uma forma de controle sobre os pais (BONGRAND, 2018). A quase totalidade das crianças está, portanto, na escola antes dos 6 anos e mesmo a partir dos 3, após as reformas realizadas por Emmanuel Macron, em 2019. Na França, portanto, 99\% dos pais e responsáveis legais pelas 8,3 milhões de crianças submetidas ao ensino obrigatório estão em contato com a escola pública ou privada contratada pelo Estado. Em comparação com a escola, apenas 42,8\% dos lares tinham rendimentos tributáveis em 2016 e, portanto, deviam praticar a instituição fiscal. Como o imposto costuma ser descrito como uma das principais instituições de controle das populações na França e na Europa ocidental em geral, esses dados atestam que a influência e o alcance social da instituição escolar são bem maiores. 
Uma das consequências dessa centralidade da escola na economia das instituições estatais na França tem a ver com seu papel socializador, não somente sobre as crianças, como inúmeros trabalhos enfatizam, mas também sobre seus pais. Moldando os padrões de percepção e avaliação do mundo social e capaz de formar as representações e práticas políticas, esta socialização política pela instituição, ligada ao papel de "pais de alunos" na escola, não é unívoca e abrange diferentes dimensões. Uma delas corresponde a uma vertente cívica e política que tende a levar os pais mais envolvidos com a instituição a estarem, ao mesmo tempo, entre os mais conformados ao ideal do "bom cidadão", interessados pela política e participando regularmente dela (sobre o aspecto eleitoral e em diversas atividades escolares). Devido à presença prolongada dos pais de alunos na instituição (sobretudo entre as classes sociais mais abastadas), suas experiências da escola e das reformas das políticas escolares favorecem a transmissão, muitas vezes tácita, de normas de cidadania e comportamentos prescritos pela instituição, que podem ter consequências propriamente políticas. Esse processo opera, evidentemente, de várias formas de acordo com o meio social, as experiências anteriores com as instituições de Estado (inclusive políticas) e os contextos geográficos (por exemplo, em áreas urbanas ou rurais). Mas as pesquisas etnográficas de longo prazo junto a famílias de origens sociais muito variadas sugerem que esta socialização política pela escola passa por experiências convergentes dentro da instituição escolar e enquanto "pais de alunos". A vida política comum também se dá na escola para os pais (BUTON et al., 2016). É a forte influência social desta instituição na França que justifica nosso interesse por ela enquanto instância de (des)politização dos pais de alunos. Essa socialização política por meio da escola repousa em três processos interligados.

\section{O Peso do Diploma e da Socialização Escolar sobre a Politização Legítima}

Um primeiro processo que contribui para a socialização política pela escola na França, talvez o mais esperado desde as obras de Pierre Bourdieu (1979) e Daniel Gaxie (1978), trata dos posicionamentos incorporados pelos pais ao longo de sua própria trajetória escolar. Ainda hoje, no contexto francês, o diploma e o capital cultural em geral (que é constituído em grande parte pelos componentes escolares adquiridos na instituição) são centrais para explicar o interesse declarado pela política, o acompanhamento das notícias políticas e a participação política convencional (através do voto ou do engajamento partidário). Independentemente dos contextos estudados, os pais de alunos com maior escolaridade são também aqueles que dizem acompanhar mais as atividades políticas, se interessar pelas campanhas eleitorais, estar a par das transformações das políticas públicas etc. Uma mãe solo, juíza, não sindicalizada, portadora de um Master 2 e formada na Escola Nacional de Magistratura, explica:

"A política é muito importante. Eu faço aquilo que posso. Às vezes falta tempo, mas leio o Le Monde todos os dias no transporte público [...] Acho que é muito importante se manter atualizado, acompanhar o mínimo. Porque há muitas coisas que dizem respeito a todos os cidadãos e é preciso estar preparado [...] evidentemente, a escola é um tema hiperpolítico".

Por outro lado, quando descemos na hierarquia social para tratar dos pais com menos escolaridade, percebemos que a tendência é que a relação com a política formal seja bem mais distante. Formulações como "isso não me interessa”, "na verdade, não dou a mínima para isso, é só blá blá blá", "que eles façam o que bem entenderem, minha vida não muda", "eu nunca voto, é um baile de máscaras para as pessoas da cidade" etc. são numerosas, e crescentes, nas entrevistas com pais de alunos sem diplomas e com trajetórias escolares mais curtas e menos exitosas (ver também LOMBA, 2018). A pesquisa confirma, assim, que os posicionamentos 
quanto à política oficial são fortemente determinados, sem exceção, pelas experiências escolares e recursos culturais. A socialização pela escola ao longo da trajetória escolar dos pais tem, portanto, efeitos de longo prazo sobre sua relação com a política.

Nesse sentido, os pais que têm a trajetória escolar mais longa e dispõem de maior capital cultural são também aqueles que mais associam a escola a uma questão política, em contraste com as famílias de menor escolaridade. Assim, na pesquisa quantitativa "Preface" realizada na França metropolitana em 2017, os mais escolarizados consideram, com mais frequência que os demais, a educação como uma das três funções mais importantes do Estado ${ }^{3}$. Quer sejam homens ou mulheres, os mais escolarizados são os que mais consideram a escola como uma função do Estado: essa associação é feita por metade das pessoas que tem pelo menos um bac $+2^{4}$ $\left(49 \%,+11\right.$ pontos em relação à média) e por até $54 \%$ das pessoas que têm pelo menos um bac $+3^{4}$, contra $29 \%$ dos sem diploma ou título de CAP/BEC (Certificado de atitude profissional e Certificado de estudos profissionais). Os entrevistados que se declararam "à esquerda" também consideram sobretudo a escola como uma função estatal. 58\% dos entrevistados que se posicionam mais à esquerda ( 0,1 na escala) e $46 \%$ dos que se declaram à esquerda $(2,3,4)$ consideram a Educação como uma função importante do Estado, contra 29\% dos entrevistados que se posicionam à direita. A escola é incluída com mais frequência entre as atribuições do Estado pelos mais escolarizados e, secundariamente, nos círculos que mostram preferências à esquerda. A pesquisa etnográfica com os pais de classes populares, sobretudo entre os de menor escolaridade, mostram, por contraste, que a ligação entre a escola, o Estado e a política é muito mais tênue, senão inexistente, nesses círculos, como ilustra o caso de Maimouna. Com 32 anos, desempregada há vários anos, ela vive com benefício social e reside num hotel social em Paris. Filha de imigrantes senegaleses, muçulmana, ela não tem diploma e cria sozinha seus dois filhos depois que seu ex-marido voltou para o Senegal. Ela não é militante. Apresentada por uma associação de pais de alunos, Maimouna está fortemente envolvida na vida escolar de seus filhos, sobretudo do mais velho, no CM15. Numa conversa informal, ela contou:

Maimouna: [Numa reunião de volta às aulas, anteontem], a professora falou sobre como ela iria trabalhar este ano. Porque cada professor faz do seu jeito. Bom, isso eu sei, estamos acostumados. E depois de um tempo, ela explicou que os pequenos do $\mathrm{CP}$ iam precisar de mais espaço na escola porque tinham lhes dado classes pequenas com poucas crianças ${ }^{6}$, e que, na verdade, os alunos do CM2, como Assane [seu filho], eram mais numerosos em sua classe. Por causa de uma lei nacional ou algo assim. Francamente, não entendi muito bem, não entendo o que a lei tem a ver com isso... parece que ela falou isso para não assumir para a diretora que eles colocaram muita gente na sua classe e isso não é bom...

Entrevistador: É a política...?

Maimouna: Não sei muito bem. Mas, sinceramente, isso me chocou, não entendi muita coisa. Lá, na escola, nós falamos da escola, das crianças, do seu futuro. E não entendo o que a lei ou a política têm a ver com isso. Acho que é uma desculpa.

Entrevistador: Você acha que a escola está fora da política, da lei, de tudo isso?

Maimouna: Sim, sim.

Entrevistador: A escola do bairro, você acha que é um pouco como o Estado e os serviços públicos também?

Maimouna: O serviço público talvez, mas acho que o Estado não. 
Assim, o primeiro processo de socialização política pela escola refere-se à trajetória escolar dos pais de alunos que, sob a forma de posicionamentos relativamente estáveis, constitui uma das principais fontes de desigualdades políticas na França, em prejuízo das classes populares (BARRAULT-STELLA; PUDAL, 2019). A capacidade de se interessar pela política (em sua definição oficial), de se engajar politicamente, mas também de militar em associações de pais de alunos ou de se organizar coletivamente para resistir às reformas escolares varia muito dependendo dos grupos sociais e de seus recursos escolares, em benefício dos grupos sociais com maior escolaridade. As desigualdades sociais se refletem aqui na ordem política sob a forma do acompanhamento das atividades políticas e das chances de mobilização. Mas além dessa forma de socialização política pela escola decorrente das experiências passadas na instituição, é também através das atividades rotineiras da escola francesa, experimentadas no cotidiano pelos pais de alunos, que a instituição produz, segundo os casos, a (des)politização.

\section{"Bons Pais" ou "Bons Cidadãos"? A Socialização dos Pais Mobilizados na Escola como uma Conformação Política}

Um segundo processo contribui para a socialização política dos pais pela instituição escolar na França: a prescrição de papéis feitas de forma rotineira aos "usuários" da instituição, ou seja, às mães (e aos pais em menor medida $)^{7}$ e principalmente aos mais presentes cotidianamente na escola. Essa socialização contribui para moldar os comportamentos políticos dos pais, em particular daqueles eleitos, militantes de associações reconhecidas ou muito engajados na escola de seus filhos. No entanto, esses pais de alunos geralmente estão situados nas classes sociais elevadas, sobretudo com maior capital cultural. Através das normas veiculadas de forma difusa pela escola, essa socialização pouco pensada orienta esses pais (que também são cidadãos) no sentido da moderação política e na direção de modos de expressão política aceitáveis e canalizáveis. Assim, as pesquisas etnográficas de longo prazo com pais de alunos mostram que, na França, o engajamento político em torno da escola tem a tendência de produzir a conformidade com a ordem institucional. É o trabalho de conformação política pela instituição escolar que se destaca aqui e este é muito mais eficaz porque afeta pais "bem" relacionados com a instituição, como observamos nos meios sociais dominantes e entre os mais escolarizados.

A socialização pelo dispositivo eleitoral, por analogia entre o universo escolar e político, constitui um exemplo desta "boa" politização encorajada pela instituição. Assim, uma primeira experiência enquanto "usuário" da escola, que contribui para a difusão de normas políticas, diz respeito à eleição de pais de alunos organizada anualmente pelo Ministério da Educação. Todo mês de junho, o ministério envia instruções às Reitorias e Inspetorias Acadêmicas sobre a organização dessas eleições de pais, que acontecem em todos os estabelecimentos escolares ao longo do mês de outubro. A participação geral nessas eleições caiu na França nas últimas décadas, sobretudo no collège (4 últimos anos do ensino fundamental, entre 11 e 14 anos). No ensino primário, a participação era de 51\% em 1977, contra 47\% em 2018. No ensino secundário, $45 \%$ em 1977, contra 22\% em 2018. Esse crescimento diferencial da abstenção está ligado à entrada massiva das classes populares no segundo grau a partir dos anos 1970 (BARTHÉLÉMY, 1995). A aculturação quanto às eleições dentro da escola varia fortemente segundo o meio social das famílias, com desvantagens para as classes populares e das minorias étnico-raciais. Mas isso reflete mais globalmente a estrutura de participação nas eleições políticas na França contemporânea (BRACONNIER; COULMONT; DORMAGEN, 2017). Como explica uma mãe de família de 34 anos, não militante, desempregada e originária do norte da África, na saída de uma escola parisiense na semana das eleições de pais de 2018: "Eu não voto nisso. Eu sei que existe, 
sabemos de tudo, mas não damos a mínima... Deixamos isso para os outros. Mas nas eleições de verdade eu voto!" Mesmo no caso de abstenção nas eleições da Educação nacional, os pais conhecem a existência do dispositivo e tendem a naturalizá-lo: "é normal que a diretora da escola eleja pais para ficarem na escola", acrescenta a mesma mãe. Um pai, arquiteto, também ativista político do Partido Socialista (PS) e eleito na mesma escola responde: "é a democracia escolar! Todo ano, prestamos contas aos eleitores e isso é ótimo!". Os pais mais presentes na escola acreditam que é "muito normal" ter representantes eleitos que levam suas demandas e queixas para a direção: "é para isso que servem os eleitos". Apesar das variações segundo as origens sociais e mesmo quando as famílias não votam, o próprio fato de organizar eleições, de delegar sua voz a representantes e a valorização de uma norma participativa parece evidente para muitos pais de alunos. A socialização dos pais pela instituição escolar tem, portanto, componentes diretamente políticos.

Além do voto, as prescrições cotidianas do papel dos pais de alunos pelos profissionais da escola contribuem para moldar suas maneiras de se mobilizar politicamente em torno da instituição, e às vezes até fora dela. As rotinas de funcionamento da instituição de ensino francesa, não só as relações com seus profissionais (em primeiro lugar, os professores) mas também com outros pais através de mecanismos bem conhecidos de socialização por conformismo (LITT, 1963; ADLER; ADLER 1998), tendem a favorecer a aprendizagem de uma forma de docilidade política entre os pais de alunos mais mobilizados em torno das questões escolares. Há "boas" maneiras de se mobilizar, e, portanto, maneiras "ruins", como veremos na última parte. Um tal resultado, no entanto, requer mais esclarecimentos e seria equivocado interpretar esses processos de maneira unívoca. Embora implique uma certa docilidade e conformidade, a socialização política ligada ao papel desempenhado pelos pais, geralmente os mais bem posicionados socialmente que são os mais presentes no cotidiano da escola, não os impede de criticar a instituição, de se opor às políticas implementadas ou de resistir de diversas manerias às reformas. Isso se comprova pelas inúmeras mobilizações observadas, tanto na cidade como no meio rural, desde os anos 2000 (p. ex., BARRAULT-STELLA, 2015). No entanto, nos sistemas políticos democráticos como a França, a instituição de ensino aceita as mobilizações dos pais de alunos e tolera os protestos... desde que adotem certas formas que são valorizadas ou toleradas. Além disso, a socialização institucional dos pais de alunos os leva a valorizar certos modos de ação, mesmo que contestadores, em detrimento de outros que são considerados ilegítimos. Embora a escola francesa não seja uma instituição uniforme, podemos citar, por analogia, as análises de Erving Goffman sobre as "adaptações secundárias”: “as adaptações 'integradas' [...] aceitam as estruturas institucionais existentes sem pressionar por uma mudança radical, e [...] podem ter a função evidente de conter forças que seriam, de outra forma, desintegradoras" (GOFFMAN, 1986a, p. 255). Essas forças "desintegradoras" são aquelas "cujos autores têm a firme intenção de abandonar a organização ou de modificar radicalmente sua estrutura, e que conduzem, nos dois casos, à ruptura do bom funcionamento da organização" (GOFFMAN, 1986a, p. 255). Nesse sentido, acompanhar os pais de diferentes escolas durante vários anos permitiu identificar não somente os modos de ação que eles mobilizam, mas também aqueles que eles evocam sem concretizar ou ainda aqueles que eles nem consideram. Levando em conta as restrições institucionais que pesam sobre os pais, podemos reconstituir o espaço do possível e do pensável em termos de expressão de descontentamento. Nesse sentido, os modos de ação "integrados” à ordem institucional, que aceitam as estruturas existentes sem pressionar por uma mudança radical segundo a fórmula de E. Goffman, são de longe os mais valorizados e os mais mobilizados pelos pais "mais bem" socializados pela instituição, como encontramos nas classes médias e altas.

Assim, a instituição escolar molda até mesmo os comportamentos de protesto dos pais de alunos, valorizando os modos de ação (incluindo a crítica) que se orientam para canais que podem ser controlados pelos detentores do poder sobre a instituição. A crítica tem suas condições de conformidade. A pesquisa mostrou que, quando os pais se opõem coletivamente a uma reforma (como o fechamento de uma classe, a mudança dos ritmos escolares, a não substituição de um professor etc.), a relação de força com a instituição e as modalidades de negociação conduzem sempre as famílias a adotarem modos de ação rotineiros, circunscritos e não "desintegradores" da instituição. A 
estrutura institucional e as interações com os profissionais geralmente levam os pais de alunos descontentes a valorizarem certas práticas contestatórias, a limitar as ações radicais e, por fim, a moderar os protestos. Observamos a princípio uma moderação geral dos conflitos com a instituição escolar na França. Se compararmos os conflitos com a escola àqueles relativos a outras instituições públicas, a pesquisa quantitativa Preface mostra que os pais de alunos vivem sua relação com a escola de maneira menos conflituosa do que com outras instâncias do Estado. A polícia e a justiça são duas instituições particularmente criticadas na França e os conflitos declarados com as autoridades fiscais (cerca de $45 \%$ dos entrevistados) são muito mais numerosos do que aqueles com profissionais da escola. Apenas $23 \%$ dos pais de alunos declararam discordar de uma decisão dos professores.

Além dessa eufemização dos conflitos com a escola, a pesquisa mostra que a contestação dos pais adota com mais frequência formas valorizadas pela instituição escolar: encontros com professores ou com a direção, uma preferência pela palavra escrita (comunicados oficiais, demandas de apoio aos eleitos locais, quer sejam municipais, departamentais ou parlamentares), alguns modos de divulgação que exigem uma eufemização das queixas (artigos de imprensa, petições, mensagens nas redes sociais etc.). E, quando se trata de as famílias se oporem frontalmente aos atores da instituição de ensino, o método de contestação por excelência é o recurso ao tribunal administrativo (daí o forte crescimento na França nos últimos vinte anos do "direito escolar"). Essa forma de expressão das queixas dos pais é até mesmo preferida pelos agentes da administração escolar: "se as associações de pais se opõem a uma decisão que acreditam importante e não compreendem nossos argumentos, elas sempre podem entrar com um recurso. Às vezes, até sugerimos isso", disse um diretor da administração escolar em 2013. Assim, quando os pais contestaram a decisão da administração de não abrir uma classe num estabelecimento superlotado, um responsável de serviço terminou assim sua entrevista à imprensa local: "As razões são claras, acredito. Se os pais não entendem, eles podem entrar com um recurso no tribunal. Não tem problema eles fazerem isso". Esse tipo de recurso à lei para expressar sua insatisfação, ou ainda para contatar o superior hierárquico, é abundante nos territórios estudados. É um modo de protesto valorizado pela instituição escolar e que se integra perfeitamente à ordem institucional. O modo de ação contestatória mais "radical" autorizado pelos atores da Educação nacional é, sem dúvida, a ocupação simbólica da secretaria de uma escola, sem violência e sem perturbar excessivamente seu funcionamento. Por exemplo, quando as famílias do polo cultural das classes médias se mobilizam contra o fechamento da escola local, o professor as incita a ocupar o estabelecimento. É desnecessário dizer que esse tipo de ação, quase rotineira na instituição, é pacífica. Essa tendência de conformação às vezes passa por tensões, mas a relação de força com a instituição e as modalidades das negociações levam quase que sistematicamente as famílias a adotarem modos de ação não "desintegradores" para a instituição.

Além disso, tudo acontece como se a escola francesa ajudasse a moldar as formas de mobilização política dos pais, sobretudo dos grupos sociais mais escolarizados, no sentido da moderação e da canalização de seu descontentamento. A instituição de ensino contribui nesse sentido com a "boa" politização dos pais de alunos. Mas essa socialização institucional que produz a conformidade não encontra condições de sucesso (GOFFMAN, 1986b) em todos os grupos sociais e, em certos meios populares, sobretudo, seu alcance acaba sendo menor.

\section{O Desajuste das Formas Populares de Mobilização e seus Efeitos Sobre a Socialização Política}

Um terceiro processo alimenta mais indiretamente a socialização política de certos pais de alunos pela instituição de ensino na França. De fato, se a escola prescreve papéis e estes se impõem com sucesso nos meios sociais mais escolarizados, eles se mostram menos operantes entre os pais que têm uma relação de maior exterioridade com a instituição, como vemos em algumas classes populares. E isso porque inúmeras 
famílias populares, especialmente aquelas pertencentes a minorias étnico-raciais (ICHOU, 2018), foram menos socializadas pela instituição escolar, não somente por suas trajetórias escolares mais curtas, mas também porque elas participam menos enquanto pais de alunos das atividades valorizadas pela instituição (responsabilidade eletiva nas escolas, encontros com a direção, participação nas associações etc.). Não se trata de alimentar um mito bastante conhecido na França e politicamente redutor da "resignação das famílias populares" (LAHIRE, 1995, p. 270-273). O desafio é, antes de mais nada, esclarecer os potenciais desajustes entre as expectativas da instituição de ensino e do campo político sobre as formas do "bom" engajamento dos pais e cidadãos. Os meios populares não são passivos nem em matéria de educação, nem no domínio político, mas suas formas de mobilização costumam ser obscurecidas pelas abordagens mais legitimistas (GRIGNON; PASSERON, 1989). No entanto, as pesquisas realizadas ao longo do tempo com famílias populares atestam que, independentemente dos contextos locais, as classes populares, em sua diversidade, sobretudo os estratos menos estáveis (SCHWARTZ, 1998), parecem ter pouca chance de se mobilizar de maneiras politicamente aceitáveis para a instituição escolar. Suas formas de mobilização e, quando aplicável, de expressão de descontentamento diante das reformas escolares costumam ser deslegitimadas e consideradas inadmissíveis pelos atores da instituição e, mais geralmente, pelas autoridades políticas ${ }^{8}$.

De fato, vimos na parte anterior que os pais mais escolarizados e mais engajados no cotidiano das escolas conseguem geralmente se fazer ouvir mais porque adotam modos de ação política considerados aceitáveis, como o recurso à escrita, a ênfase na moderação e até mesmo o recurso ao direito como forma última de contestação, integrada à ordem institucional. No entanto, em contrapartida, os modos de ação menos ajustados às rotinas da instituição escolar e considerados mais "radicais" são amplamente deslegitimados pelos atores institucionais bem como pelos outros pais que, em grande parte, interiorizaram os limites do aceitável para protestar na instituição. Uma mobilização de famílias populares com níveis desiguais de estabilidade, de minorias étnico-raciais, que reivindicava a abertura de uma classe num bairro do norte de Paris, em 2018, ilustra bem isso. Enquanto os pais mobilizados, que não tinham experiências anteriores de militância, lutavam há várias semanas, um pai de origem malinesa perdeu a paciência durante uma reunião com a diretora, com representantes da hierarquia do Ministério da Educação e eleitos locais:

Chefe da administração escolar: A conclusão de tudo isso é que não vamos poder resolver isso este ano, porque não temos os meios, na verdade. Mas no ano que vem, estaremos atentos e observaremos a situação de perto. Com prioridade, é claro.

Um funcionário municipal eleito: Sim, é preciso entender que nossos parceiros do Ministério da Educação fazem o que podem com suas restrições... A prefeitura vai acompanhá-los o ano inteiro...

A diretora da escola: Na verdade, vejo que não temos outras opções para o início do ano letivo. E estamos com um pouco de urgência...

Um pai, trabalhador, de origem malinesa: Pff... vocês não passam de um bando de mentirosos. Não acredito que vocês vão resolver isso (levantando-se com raiva...). Para mim, esse é mais um golpe, não aguento mais. Danem-se vocês.

Sua atitude, considerada deslocada e violenta, foi firmemente condenada pelo conjunto dos presentes. Os outros pais mobilizados se disseram também ofendidos, temendo que sua mobilização fosse totalmente deslegitimada por causa do comportamento dele. No dia seguinte, esse mesmo pai propôs ao 
coletivo de pais de alunos de "irem à reitoria criar confusão". Considerando esse modo de ação desajustado e preocupados em ter credibilidade nas negociações com a administração escolar e com os eleitos locais, os outros líderes do coletivo de pais, essencialmente mães de origem norte-africana que são também as mais engajadas na escola popular do bairro nos últimos anos, recusaram categoricamente. As discussões acaloradas duraram uma boa meia hora e o pai em questão finalmente deixou o coletivo, sozinho, considerando os outros pais "muito moles". As lutas sobre as formas de mobilização coletiva conduziram, portanto, a um reenquadramento e, em seguida, à expulsão do pai que propunha modos de ação muito radicais, não apenas por causa de sua deslegitimação pelos atores políticos e administrativos, mas também e sobretudo por que os outros pais foram socializados anteriormente de maneiras aceitáveis para se fazerem ouvir na instituição.

Essa clivagem reproduz divisões internas das classes populares do bairro, opondo frações estáveis aculturadas a modos de ação admissíveis (os outros pais mencionados) e outros menos estáveis caracterizados por mais exterioridade com a instituição (o pai em questão). Mesmo em caso de forte protesto, a escolha das armas pelos pais de alunos continua estruturada por sua socialização institucional. E não é por acaso que este pai de aluno de origem malinesa, sem diploma e que não foi escolarizado na França, propõe modos de ação desajustados: é a primeira vez que participa de uma mobilização coletiva em torno da escola e quase não foi socializado pela instituição, costumando deixar sua mulher administrar as questões escolares (SIBLOT, 2006). A socialização institucional dos pais de alunos os afeta ainda mais quando eles próprios frequentam ou já frequentaram a escola (BARRAULT-STELLA, WEILL, 2018). Quanto mais prolongada é esta socialização, mais os pais são levados a exprimir suas queixas sob formas possibilitadas pela ordem institucional. E viceversa no caso de certas famílias populares que, por sua vez, encontram-se frequentemente na situação de não se fazerem ouvir e de verem seus interesses sociais negados pelos atores institucionais.

A repetição desse tipo de experiência não ocorre sem um policy feedback (efeito devolução: PIERSON, 1993), não controlado e indireto, sobre a socialização política dos pais. Isso contribui até mesmo para moldar suas visões de mundo e seu posicionamento em relação às instituições públicas, inclusive políticas. Esta tendência de impossibilidade de se fazerem ouvir e influenciar as políticas escolares tem fortes implicações para os pais já precarizados das classes populares que, em consequência, são levados a se distanciar ainda mais da escola e, mais amplamente, a adotar comportamos de evasão (HIRSCHMAN, 1986) de vários espaços institucionais. É o ceticismo político que impera nessas famílias populares, exacerbando sua tendência de afastamento das atividades políticas. Procurado alguns meses depois da disputa, o pai operário de origem malinesa citado anteriormente relatou um distanciamento maior não só da escola local ("desde essa história, eu não dou mais a mínima, não passo do portão [da escola] e não vou mais a nenhuma reunião da diretora ou de pais"), mas também de outras instituições políticas ("a política é sempre a mesma história, tem as pessoas que contam, os ricos, os brancos que têm o poder, e os outros como nós. Mas eu não me envolvo nas coisas deles". E, de fato, esse pai se absteve sistematicamente de votar e não relatou nenhuma forma de engajamento cidadão, não por incompetência, mas por uma recusa estratégica. Não se trata de um caso isolado, e outros pais das classes populares, decepcionados com o fato de as autoridades escolares não levarem em conta seu ponto de vista, experimentam posturas muito semelhantes de desilusão em relação à política. O caso de Nathalie, mãe solo de 27 anos, não militante, empregada de meio período de um supermercado no meio rural no sul da França, onde a escola local foi fechada no ano anterior apesar do protesto dos pais, conta: "eu não acredito mais nem um pouco na política. Não que eu acreditasse muito antes. Mas às vezes, achamos que isso pode dar certo, que pode ser justo. Não passa de palavras bonitas. O fechamento da escola no ano passado foi a gota d'água [...] Apesar de nossas demandas, nossas insistências, nosso sofrimento, eles não deram a mínima e fecharam... Que não me peçam nada agora [...] Nem mesmo votar, não vou mais”. 
No entanto, esse policy feedback "negativo" (FERNANDEZ, JAIME-CASTILLO 2013) não se limita à desconfiança e ao afastamento das questões políticas. Muitos casos encontrados ao longo das pesquisas atestam que outro efeito das decepções dos pais das classes populares rejeitados pela instituição escolar é orientá-los na direção de organizações políticas de extrema direita. Uma amiga de Nathalie, que vive no mesmo município onde a mobilização das famílias populares não impediu o fechamento da escola, passou a ter preferências, acentuadas ao longo do tempo, pelo RN (Rassemblement National, antigo Front National) durante as eleições nacionais. Ela conta: "aqui podemos morrer de fome e ninguém liga. Faz 40 anos que dizem que somos caipiras que viviam no deserto. Não tem trabalho, não tem nada. Eles acham jeitos de retirar o pouco que temos. O correio, a escola, os comércios. O que aconteceu com a escola era o que faltava para o vilarejo, isso acabou comigo [...] A única que fala disso tudo é Madame Le Pen [a presidente do RN, que chegou ao segundo turno da eleição presidencial de 2017]. Então, vou dizer, não tenho vergonha, votei nela, e não foi a primeira vez e não vai ser a última. Se ela for eleita, pelo menos isso vai sacudir as coisas e vai esquentar". Este não um caso único e o RN atinge números especialmente altos nas classes populares (MAUGER; PELLETIER, 2017), sobretudo em certos contextos rurais (CLOTEAU et al., 2020) caracterizados por uma retirada do Estado e dos serviços públicos, como em um dos territórios estudados. Embora se deva destacar que o poder eleitoral da extrema direita francesa está longe de ser responsabilidade exclusiva das classes populares $^{9}$ (COLLOVALD, 2004), as pesquisas realizadas junto a famílias populares do meio rural mostram que a retirada do Estado desse tipo de contexto, fruto de reformas implementadas há várias décadas, bem como a negligência em relação às demandas populares alimentam a desconfiança geral em relação ao sistema político ou até mesmo, em alguns casos, o aumento do apoio à extrema direita.

\section{Conclusões}

No geral, o cruzamento de várias pesquisas etnográficas realizadas ao longo de anos com pais de alunos permite trazer o foco para as desigualdades dos processos de socialização política pela escola na França. Nesse país da Europa ocidental, a instituição escolar goza de uma influência social considerável devido à obrigatoriedade do ensino e às modalidades de organização do sistema de ensino, que está quase que exclusivamente sob tutela do Estado. Esta particularidade está obviamente ligada à trajetória histórica do Estado de bem-estar social na França (ALBER, 1988; DE SWAAM, 1998; ESPING-ANDERSEN, 1990), mas torna esse contexto nacional um "caso" interessante para observar a maneira pela qual uma instituição como a escola contribui para a socialização política de seus "usuários", no caso, os pais de alunos.

A educação dos comportamentos políticos e as instâncias de socialização que geram posicionamentos políticos não se reduzem, nem na França nem em outros lugares, às dinâmicas da escola. Mas esta pesquisa insiste sobre o peso dessa instituição singular, já esperado no caso dos alunos, e menos no caso dos pais. O emprego de métodos qualitativos junto aos sujeitos da pesquisa que, em sua maioria, não são ativistas políticos regulares, enfatiza que, ao menos na França, a escola molda os esquemas de percepção do mundo social e os posicionamentos políticos dos pais de alunos de forma estruturalmente desigual segundo os grupos sociais ${ }^{10}$. De acordo com as pesquisas etnográficas realizadas, que sem dúvida não esgotam a diversidade dos casos observáveis, a instituição constitui uma das principais instâncias estatais de formação das modalidades de participação política e da definição de normas de comportamento do "bom cidadão", ativo politicamente (mas não muito) e mobilizado de formas suscetíveis de serem controladas pelos detentores do poder político. Além da aprendizagem possível na estrutura dos instrumentos participativos, como formas de politização potencialmente importadas do engajamento em movimentos sociais ou outras organizações, essa socialização 
política pela escola no cotidiano repousa, no contexto francês, em três processos interligados: os traços incorporados pela socialização escolar dos pais ao longo de sua própria trajetória escolar; as prescrições de papeis feitas no cotidiano aos pais de alunos que traçam os contornos do que a instituição considera "bons" pais e cidadãos e afetam prioritariamente as famílias presentes na escola e relativamente dóceis, como encontramos nos meios mais abastados; e as consequências políticas dos fracassos e decepções experimentados pelas famílias populares em torno da escola, que tendem a alimentar seu ceticismo político e até mesmo sua "radicalização" para a extrema direita.

Compreendemos que se tratam de socializações políticas muito desiguais de acordo com as classes sociais e o grau de conformidade à ordem institucional. Certas formas de politização são apreciadas, alimentadas e encorajadas (como o voto) pela instituição escolar. Enquanto outras (como o confronto verbal), observadas singularmente nos meios mais modestos, são consideradas inaceitáveis e não são toleradas. $\mathrm{O}$ sufocamento das classes populares contribui, por sua vez, à socialização política descontrolada e suscetível de beneficiar os candidatos políticos da extrema direita. Não é improvável que esse tipo de processo de educação política pelo fracasso das mobilizações populares se encontre em outros contextos que aqueles observados na França.

\section{Notas}

1. Este texto é uma introdução a um dos eixos de análise da Habilitação em Condução de Pesquisas que preparo no Laboratório CRESPPA-CSU do CNRS, na França.

2. Ver as oportunidades e os obstáculos institucionais analisados por (MAZEAUD, 2012) no caso dos orçamentos participativos dos liceus.

3. A pergunta feita foi: "Quais são as três funções do Estado que você considera mais importantes?" Agradeço a Cédric Hugrée pelas análises estatísticas.

4. Baccalauréat, conhecido como "bac" é uma qualificação acadêmica que estudantes na França, ao final do liceu, precisam obter para ingressar no ensino superior. $\mathrm{Bac}+2 \mathrm{ou} \mathrm{Bac}+3$, indicam que a pessoa possui o Bac e cursou mais 2 ou 3 anos de ensino superior.

5. A escola primária ou elementar é composta na França por 5 anos, ao longo dos quais os alunos têm, em geral, entre 6 e 10 anos de idade: CP, CE1, CE2, CM1 e CM2.

6. Ela faz alusão à reforma do desdobramento de classes de $\mathrm{CP}$ em zonas de educação prioritária introduzida em 2017.

7. Assim, enquanto na França a taxa de adesão a uma associação desse tipo é de 7\% dos pais em média, essa taxa é de $10 \%$ para as mulheres contra $5 \%$ para os homens.

8. Isso não exclui a possibilidade de que, em certos casos, existam mobilizações populares em torno da escola recebidas favoravelmente pela administração, ver por exemplo (VAN ZANTEN, 2001).

9. A votação popular para o RN não pode ser exagerada: "contrariamente a uma tese já bem consolidada, o FN não é a escolha majoritária dos operários e apenas uma pequena minoria deles (menos de um a cada sete) cedeu nas últimas eleições à tentação frontista, seja reintegrando na análise os não-inscritos ou abstenções, uma propensão em última instância inferior à dos independentes" (LEHINGUE, 2017, p. 37).

10. Minhas pesquisas visam documentar mais precisamente a influência das desigualdades sociais, de gênero e raça nesse processo de socialização política pela escola. 


\section{Referência}

ADLER, P. A.; ADLER P. Peer power. New Brunswick: Rutgers University Press, 1998.

ALBER, J. Continuities and changes in the idea of the Welfare State, Politics \& Society, California, v. 16, n. 4, p. 451-468, 1988. https://doi.org/10.1177/003232928801600403

BARRAULT-STELLA, L. Gouverner par accommodements. Stratégies autour de la carte scolaire. Paris : Dalloz, 2013.

BARRAULT-STELLA, L. Des groupes d'intérêt à l'École. Les collectifs locaux de parents délèves dans la fabrique de laction publique éducative. In: CADIOU, S. (dir.). Gouverner sous pression ? La participation des groupes d'intérêts aux affaires territoriales, Paris: Lextenso-LGDJ, 2015. p. 205-218.

BARRAULT-STELLA, L. Sciences politiques et éducation. In : VAN ZANTEN, A.; RAYOU, P. (dir.). Le dictionnaire de l'éducation. Paris: PUF, 2017. p. 784-789.

BARRAULT-STELLA, L.; LEHINGUE, P. Affinités électorales. Actes de la Recherche en Sciences Sociales. Paris: Le Seuil, 2020. n. 232-233.

BARRAULT-STELLA, L.; PUDAL, B. Retour sur la politisation des classes populaires. Propositions pour une analyse des états de matière du politique et de leur convertibilité. In: BARRAULT-STELLA, L.; GAITI, B.; LEHINGUE, P. (dir.). La politique désenchantée ? Rennes: PUR, 2019. p. 105-128.

BARRAULT-STELLA, L.; WEILL P. E. (eds.). Creating target publics for welfare policies. A comparative and multilevel approach. Cham: Springer, 2018. 208 p.

BARTHÉLÉMY, M. Des militants à l'école. Les associations de parents d'élèves en France. Revue Française de Sociologie, Paris, v. 26, n. 3, p. 439-472, 1995. https://doi.org/10.2307/3322164

BOURDIEU, P. La distinction. Critique sociale du jugement. Paris : Minuit, 1979.

BONGRAND, P. (dir.). Instructions en famille: Explorations sociologiques d'un phénomène émergent. Revue Française de Pédagogie, Paris, n. 205, 2018. https://doi.org/10.4000/rfp.8581

BRACONNIER, C.; COULMONT, B.; DORMAGEN, J. Y. Toujours pas de chrysanthèmes pour les variables lourdes de la participation. Revue Française de Science Politique, v. 67, n. 6, p. 1023-1040, 2017.

BUTON, F. et al. L'Ordinaire du Politique. Enquêtes sur les rapports profanes au politique. Villeneuve d’Ascq: Presses Universitaires du Septentrion, 2016.

CLOTEAU, A. et al. La banalisation du Front national au village. Actes de la Recherche en Sciences Sociales. Paris: Le Seuil, 2020. n. 232-233.

COLLOVALD, A, Le populisme du FN. Bellecombe en Bauges : Croquant, 2004.

DARMON, M. La socialisation. Paris: Armand Colin, 2007.

DE SWAAN, A, Sous l'aile protectrice de l'état. Paris: PUF, 1988.

DOUNIES, T. Parler politique en classe: Ethnographie de la socialisation politique en contexte scolaire. 
Sociétés Contemporaines, Paris, n. 114, p. 151-179, 2019. https://doi.org/10.3917/soco.114.0151

ESPING-ANDERSEN, G. The Three Worlds of Western Capitalism. Princeton: Princeton University Press, 1990.

FERNANDEZ, J. J.; JAIME-CASTILLO, A. M. Positive or negative policy feedbacks ? European Sociological Review, Oxford, v. 29, n. 4, p. 803-815, 2013. https://doi.org/10.1093/esr/jcs059

FOUCAULT, M. Naissance de la biopolitique. Paris: Gallimard/Seuil, 2004a.

FOUCAULT, M. Sécurité, territoire, population. Cours au Collège de France 1977-1978, Paris: Seuil, 2004b.

GAXIE, D. Le cens caché. Paris: Seuil, 1978.

GOFFMAN, E. Asiles. Etudes sur la condition sociale des malades mentaux. Paris: Minuit, 1986a.

GOFFMAN, E. La condition de félicité. Actes de la Recherche en Sciences Sociales. Paris: Le Seuil, 1986b. n. 64 , p. 63-78.

GRIGNON, C.; PASSERON, J. C. Le savant et le populaire. Paris: Hautes Études/Gallimard/Seuil, 1989.

HIRSCHMAN, A. O. Exit and voice: an expanding sphere of influence. In: Rival Views of Market Society and Other Recent Essays. New York: Viking, 1986. p. 87-103.

HYMAN, S. Youth and politics. Expectations and realities. New York: Basic Books, 1972.

ICHOU, M. Les enfants d'immigrés à l'école. Paris: PUF, 2018.

LAHIRE, B. Tableaux de famille. Paris: Gallimard/Seuil, 1995.

LITT, E. Civic education, community norms, and political indoctrination. American Sociological Review, v. 28 , n. 1, p. 69-75, 1963.

LEHINGUE P. Lélectorat du Front National. In: MAUGER, G.; PELLETIER, W. (dir.). Les classes populaires et le FN. Broissieux: Croquant, 2017.p. 19-42.

LOMBA, C. La Restructuration permanente de la condition ouvrière. Vulaines-sur-Seine: Éditions du Croquant, 2018.

MAUGER, G.; PELLETIER, W. (dir.). Les classes populaires et le FN. Broissieux: Croquant, 2017.

MAZEAUD, A. Allocation de l'argent public et budget participatif des lycées: règles du jeu et pratiques délibératives. Genèses, Paris, n. 88, p. 89-113, 2012. https://doi.org/10.3917/gen.088.0089

METTLER, S.; WELCH, E. Civic generation: policy feedback effects of the GI Bill on political involvement over the life course. British Journal of Political Science, London, v. 34, n. 3, p. 497-518, 2004. https://doi. org/10.1017/S0007123404000158

MCADAM, D.; TARROW, S.; TILLY, C. Dynamics of contention. New York: Cambridge University Press, 2001.

PERCHERON, A. Âge, cycle de vie, génération, période et comportement électoral. In: GAXIE, D. (dir.). Explication du vote. Paris: Presses de Sciences Po, 1989. p. 228-262. 
PERRINEAU, P. (dir.). Le vote disruptif. Paris: Presses de Sciences Po, 2017.

PIERSON, P. When effect becomes cause: policy feedback and political change. World Politics, v. 45, n. 4 , p. 595-628, 1993.

PUTNAM, R. Bowling alone: The Collapse and Revival of American Community. New York: Simon and Schuster, 2000.

RAGIN, C.; BECKER, H. What is a case ? Cambridge: Cambridge University Press, 1992.

ROSENSTONE, S.; HANSEN, J. M. Mobilization, participation and democracy in America. New York: Macmillan Publishing Company, 1993.

SCHWARTZ, O. La notion de classes populaires. 1998. Thèse (HDR en Sociologie) - Licence Sociologie, Université de Saint-Quentin-en-Yvelines, Versailles, 1998.

SIBLOT, Y. La prise en charge féminine des tâches administratives entre subordination et ressource. Genèses, Paris, v. 64, n. 3, p. 46-66, 2006. https://doi.org/10.3917/gen.064.0046

STEWART, C.; BOBO, L. D.; HOCHSCHILD, J. L. Populism and the future of American politics. American Academy of Arts and Sciences, Winter 2017 Bulletin, 2017. Disponible en: https://www.amacad.org/news/ populism-and-future-american-politics. Acesso em: 21 Jul. 2020.

TOCQUEVILLE, A. Democracy in America and two essays on America. New York: Penguin Books, 1835.

VAN ZANTEN, A., L'école de la périphérie. Paris: PUF, 2001.

VERBA, S.; LEHMAN, K.; BRADY, H. Voice and Equality: Civic Voluntarism in American Politics. Cambridge, MA: Harvard University Press, 1995.

\section{Sobre o Autor}

Lorenzo Barrault-Stella tem doutorado em Sociologia Política pela Universidade Paris 1 - Panthéon Sorbonne (2011). Ele é pesquisador do CNRS na França desde 2013 e membro do CRESPPA-CSU na Universidade Paris 8 desde 2015. Seus trabalhos tratam das sociologias de Estado, da politização e da instituição escolar. Ele publicou recentemente com Patrick Lehingue "Affinités électorales" (BARRAULT-STELLA; LEHINGUE, 2020); e, com Pierre-Édouard Weill, Creating Target Publics for Welfare Policies (BARRAULT-STELLA; WEILL, 2018). 